\title{
Legal and organizational means of innovative development of the agro-industrial complex in Russia
}

\author{
Alexander Savoskin ${ }^{1,2, *}$, Victoria Kalitskaya ${ }^{1}$, Maria Vilacheva ${ }^{1}$, Takhir Toguzaev $^{3}$, and \\ Aslan Zhemukhov ${ }^{3}$ \\ ${ }^{1}$ Ural State University of Economics, 8 March/Narodnaya Volya Str., 62/45, 620144 Ekaterinburg, \\ Russia \\ ${ }^{2}$ South Ural Federal University, Lenin Avenue, 76, 454080 Chelyabinsk, Russia \\ ${ }^{3}$ Kabardino-Balkarian State Agricultural University named after V.M. Kokov, Lenin Avenue, 1V, \\ 360030 Nalchik, Russia
}

\begin{abstract}
The performance of agriculture in Russia remains unsatisfactory, which requires the state to take active measures to support and develop it. In recent years, government policy has been focused on the formation of a high-tech agro-industrial complex, the introduction of digital means and ensuring food security. At the same time, the measures which are taken by the state do not form a single integrated system and do not ensure the achievement of the desired effect. The publication analyzes the current state of legislation in the field of agro-industrial complex support. Particular attention is paid to the Federal Scientific and Technical Program for the Development of Agriculture for 2017 - 2025. Based on the results of the research, conclusions about the need to adopt a comprehensive federal law and strengthen the role of the State Council of the Russian Federation in the development of a national agrarian policy are drawn, measures to improve legislation in the field of supporting the innovative development of agriculture are substantiated, and additional measures of state support for the agro-industrial complex in the Russian Federation are proposed.
\end{abstract}

\section{Introduction}

The current state of agriculture in Russia and the economy as a whole does not allow to get around without the active role of the state. New challenges, including the coronavirus pandemic, also actualize the role of the state in supporting and developing the domestic agro-industrial complex, especially in the area of import substitution. At the same time, the analysis of regulations leads to the conclusion that there is no unified concept of support and development of the agro-industrial complex in Russia.

At the same time, the legal regulation of the agro-industrial complex is not only extremely fragmented (which is at least inconvenient), but also does not have sufficient depth, which means that it does not fully take into account the specifics of the agricultural

*Corresponding author: savoskinav@yandex.ru 
manufactures and processors (in comparison with other types of production and processing).

The main problem of legal regulation of agricultural support is the lack of comprehensive legislative regulation. So it should be noted that despite the large scale of the 2020 constitutional reform, the country's Basic Law was not supplemented with provisions on agriculture, food security or other similar norms. There is also no specialized federal law that would define the powers of bodies of all levels of public authority in relation to agricultural manufactures and processes of raw materials. Also, the Decree of the President of the Russian Federation No. 474 dated July 21, 2020 "On the national development goals of the Russian Federation for the period up to 2030" does not say anything about agriculture.

However, it would be wrong to say that Russia is not taking measures to support the innovative development of the agro-industrial complex [1,3]. So, in the interests of the development of agriculture, the President of the Russian Federation initiated measures aimed at the implementation of the state scientific and technical policy (we are talking about the Decree of the President of the Russian Federation dated July 21, 2016, No. 350). The New Food Security Doctrine (also approved by the President of the Russian Federation dated January 21, 2020) also focuses on the innovative development of the agro-industrial complex.

The main problem is the fact that today the legal regulation of the development of agriculture is actually entrusted to the Government of the Russian Federation, which, as an executive body, is called upon to implement the agricultural policy in the country, but not to generate it. It is important to take into account that the subjects of the development and implementation of strategic positioning documents have different decision-making mechanisms and different competencies, and their artificial separation is of great managerial importance. As mentioned above, in the Russian Federation, such a division is not traced, and the main generator of the legal field for the development of the agroindustrial complex is the Government of the Russian Federation in conjunction with the Ministry of Agriculture of the Russian Federation which is subordinate to it [6].

This is clearly seen from the plenty and content of acts of the Government of the Russian Federation in the area we are analyzing, and above all, from the materials of the State Program for the Development of Agriculture and Regulation of the Markets of Agricultural Products, Raw Materials and Food (approved by the Decree of the Government of the Russian Federation dated July 14, 2012, No. N717), the Strategy for the development of the agro-industrial and fishery complexes of the Russian Federation for the period up to 2030 (approved by No. by the Government of the Russian Federation dated April 12, 2020), the Strategy for the Development of the Food and Processing Industry of the Russian Federation for the Period up to 2020 (approved by the Government of the Russian Federation dated April 17, 2012), the Strategy for Sustainable Development of Rural Areas of the Russian Federation for the period up to 2030 (approved by the Government of the Russian Federation dated February 2, 2015), the Long-term Strategy for the Development of the Grain Complex of the Russian Federation until 2035 (approved by the Government of the Russian Federation dated August 10, 2019), etc. It is noteworthy that many program documents were adopted in the form of orders of the Government of the Russian Federation, that is, as a general rule, they are not normative legal acts, which directly contradicts their purpose and content as acts of a program nature, which can negatively affect the implementation of innovative technologies in agroecosystems.

At the next level of legal regulation, there are acts directly from the Ministry of Agriculture of the Russian Federation. Among the large number of them, in relation to the development of innovative technologies in agroecosystems, one should highlight: Departmental target program "Ensuring general conditions for the functioning of the 
branches of the agro-industrial complex" (approved on July 9, 2020) and the Action Plan of the Ministry of Agriculture of the Russian Federation for 2020-2025 (approved on August 24, 2020).

At the present time, the main tool for the innovative development of agriculture and related industries the state has determined state programs and subprograms adopted for their development. Among the ones that have been implemented for a long time, one can, for example, single out the State Program for the Development of the Fisheries Industry (approved by the Government of the Russian Federation dated April 15, 2014), and relatively new is the state program for the Integrated Development of Rural Areas (approved by the Government of the Russian Federation dated May 31, 2019); federal project "Creation of a support system for farmers and the development of rural cooperation" of the national project "Small and medium-sized businesses and support for individual entrepreneurial initiative" (approved by the minutes of the meeting of the project committee dated December 11, 2018); federal project "Export of products of the agro-industrial complex" of the national project "International cooperation and export" (approved by Presidium of the Council under the President of the Russian Federation for Strategic Development and National Projects dated December 24, 2018); Federal Scientific and Technical Program for the Development of Agriculture for 2017 - 2025 (approved by the Government of the Russian Federation dated August 25, 2017).

Analysis shows that documents in the field of development of the agro-industrial complex are adopted not only by state authorities, but also by all kinds of committees, councils or presidiums under them. Which do not belong to the number of power institutions, which raises a big question about the legal force of the documents approved by them. Due to the absence of a single coordinating body, these documents have an extremely fragmented content, are not always interconnected, and therefore are difficult to analyze and evaluate in their totality. That in the future does not allow to objectively judge the real effectiveness of the efforts undertaken.

\section{Materials and methods}

The publication is based on an analysis of the regulations of the President of the Russian Federation, the Government of the Russian Federation, the Ministry of Agriculture of the Russian Federation and official statistical data (including reports of the authorities and reports of scientific organizations prepared by order of the authorities), presented on the websites of the Ministry of Education and Science of the Russian Federation, the Ministry of Agriculture of the Russian Federation, the official website of the Federal Scientific and Technical Program for the Development of Agriculture for 2017-2025, as well as on materials of open data of federal executive bodies posted in accordance with the Federal Law "On providing access to information on the activities of state bodies and local selfgovernment bodies."

Within this research, an optimal model of legal regulation of the innovative development of the agro-industrial complex in Russia is being built on the basis of the dialectical unity of its legal, general scientific (analysis, synthesis, deduction and induction, abstraction, structural-functional method) and special methods (formal-legal, method of legal construction, formal-logical, systemic, technical and legal analysis, statistical method). After that, a variant of the optimal legal regulation of the development of the agro-industrial complex of Russia was proposed. 


\section{Results and Discussion}

Perhaps the most effective and, as practice shows, a popular tool for implementing an innovative state agricultural policy is the Federal Scientific and Technical Program for the Development of Agriculture for 2017-2025 (hereinafter referred to as the Federal specialpurpose research and development programme) and the subprograms adopted in its development "Development of Potato Breeding and Seed Production in the Russian Federation "(Approved by Resolution of the Government of the Russian Federation No. 559 dated May 05, 2018); "Development of selection and seed production of sugar beet in the Russian Federation" (approved by the Decree of the Government of the Russian Federation No. 1615 dated December 21, 2018); "Creation of a domestic competitive cross of meat chickens in order to obtain broilers" (approved by Resolution of the Government of the Russian Federation No. 782 dated May 28, 2020).

At the beginning of 2021, the following industry subprograms of the Federal specialpurpose research and development program are at various stages of preparation: "Development of production of feed and feed additives for animals", "Improving the genetic potential of cattle of specialized beef breeds", "Improving the genetic potential of dairy cattle", "Improving the genetic potential of small ruminants", "Breeding and seed production of oilseeds", "Selection and seed production of vegetable crops", "Development of viticulture, including nursery growing", "Development of selection and processing of grain crops", "Development of nursery and horticulture", "Development of selection and seed production of corn", "Development of selection and seed production of industrial crops", "Development of aquaculture", "Agricultural machinery and equipment", "Development of technologies for the production of pesticides and agrochemicals of biological origin for use in agriculture", "Development of technologies for the production of medicines for veterinary use." These programs have not yet been approved by the Government of the Russian Federation, but in developing them, the key task was to create and introduce competitive domestic technologies in agriculture. The work carried out in the country to introduce new technologies in the domestic agro-industrial complex and to ensure the country's food security directly depends on the quality of the development of these subprograms and the success of their implementation [7].

Taking into account that some of the subprograms of the Federal special-purpose research and development program are already being implemented and official statistical information has appeared on them, we will analyze them for problems.

The subprogram "Development of potato breeding and seed production in the Russian Federation" is aimed at ensuring stable growth in production volumes, as well as the implementation of high-quality seed potatoes of modern competitive domestic varieties based on the use of new high-tech Russian developments and complex scientific and technical projects of a full innovation cycle. To date, 31 companies have taken part in the program and 12 new domestic competitive potato varieties have been created ("Northern Light", "Elena", "Gulliver", "Samba", "Prime", "Carmen", "Indigo", "Triumph", "Bear", "Kumach", "Varyag", "Explosive").

At the same time, the analysis of the implementation of these subprograms revealed the following problems. First, project customers often do not have the opportunity to fully utilize the allocated state support funds. This is due to both the late delivery of budget financing and organizational difficulties in the implementation of measures, in particular, the transfer of the deadlines for the execution of contracts for some obligations. Second, when using the current editions of the subprogram passports, the customers cannot confidently continue the implementation of projects, and the monitoring center and the Program Directorate face difficulties in assessing the results of the subprogram implementation (the solution to this problem is seen in the updating and approval of the 
previously approved project passports by the Program Council). Third, the participants in the subprogram do not meet the targets. Fourth, the lack of specific deadlines for communicating budget funds to customers and project participants (scientific and educational institutions). Fifth, there is a high probability of not reaching the planned values of some indicators, in particular, in terms of the number of developed plant protection products. Sixth, the lack of demand or low demand for new domestic potato varieties, difficulties in selling the obtained seed material. Seventh, the weather factor is a risk for production and can make adjustments to the implementation of projects and subprograms. Eighth, restriction of transportation and delivery of goods due to the prohibition of the movement of vehicles. Ninth, an increase in the timing of the manufacture of goods and the implementation of activities of the subprogram from suppliers due to the impossibility of timely fulfilment of obligations under agreements, contracts, conventions. Tenth, a change (fluctuation) in the exchange rate, which entails an increase in the cost of some work (for example, the purchase of material and technical values).

Elimination of existing and timely prevention of emerging risks will reduce the degree of negative influence of these factors. In order to update and bring into compliance with the schedule of the work performed, the timing of achieving the planned indexes and indicators, the 21 st customer of Complex scientific and technical program determined the need to amend the previously approved project passports. The main issue requiring a prompt decision was the approval by the Presidium of the Council of the Program of new editions of passports. For this purpose, the monitoring center analyzed the submitted new editions of passports and prepared the corresponding conclusions.

The expert group assessed the impact of the changes introduced on the achievement of the results of each project and prepared recommendations for the Program Council: the continuation of the implementation of the Complex scientific and technical program in the new edition of the passports for 18 customers was agreed (LLC "AgroStar", LLC "Zolotaya Niva", LLC "Kolpakov", JSC "Pogarskaya Potato Factory", LLC "Agrofirma Slava Potato Yalchiki ", LLC APK "Lyubovskoye", LLC "FH SeDeK", SEC "Nikolsk", LLC " Zolskiy potato", LLC "SoyuzAgro", LLC" SSK "UralskIy potato", LLC "FAT-AGRO", JSC "Ozyory", LLC "Agricultural enterprise" Dary Malinovki ", LLC TPK "Elita-potato", LLC "AgroInter", CJSC Agricultural enterprise "Michurinets", LLC "Redkinskaya APK"); Refusal to approve the implementation of the Complex scientific and technical program in the new edition of passports for 3 customers ( PJSC "Belorechenskoye", LLC "AgroSoyuz Spassk", LLC "Agrofirma" KRiMM ").

Separately, it should be noted that the issue of agreeing on new editions of passports remains very relevant, since when using outdated current editions of passports, customers cannot confidently continue the implementation of projects, and the monitoring center and the Directorate of the Program cannot monitor and control the implementation of the subprogram. Thus, the question of the algorithm and procedure for promptly making changes to the passports of the Complex scientific and technical program remains open.

The subprogram "Development of selection and seed production of sugar beet in the Russian Federation" is implemented with the aim of creating competitive hybrids of domestic selection of sugar beets based on the use of new high-tech Russian developments and the implementation of complex scientific and technical projects of a full innovation cycle, development of a system of sugar beet seed production, ensuring stable growth in volumes of industrial production and sale of high-quality competitive seeds of costeffective hybrids of sugar beet of domestic selection, the creation of modern means of diagnostics of diseases and quality control of seeds of sugar beet hybrids.

At the same time, since the start of the programme, only two enterprises have taken part in it: Federal state budgetary scientific institution "Pervomayskaya Sugar Beet Selection and Experimental Station" and Federal state budgetary scientific institution "All-Russian 
Scientific Research Institute of Sugar Beet and Sugar" named after A.L. Mazlumov", which have developed 3 new hybrids of domestic selection of sugar beet, namely: "Ruby", "Carat" and a PMC 129 diploid hybrid. In connection with the above, the Ministry of Agriculture of the Russian Federation announced in December 2020 an additional competition for the selection of complex scientific and technical projects for the provision of grants in the form of subsidies from the federal budget for the implementation of complex scientific and technical projects in the agro-industrial complex [9].

If we abstract from the nuances of the implementation of specific subprograms, then in the process of implementing the Federal scientific and technical program itself, the following systemic issues and problems arose.

First, there were questions about calculating the budget and, first of all, determining the amount of extra-budgetary funds raised for the implementation of the project. If to follow the regulatory framework, then the amount of such extra-budgetary funds for the implementation of the project should be equal to or exceed the amount of the following federal budget funds allocated for state support of the project: subsidies for the implementation of a state task in terms of project work performed by a scientific or educational organization subordinate to the executors' subprograms (with the exception of federal budget expenditures for the development of educational programs); grants in the form of subsidies from the federal budget for the implementation of the project. It is important to emphasize here that when determining the volume of actually attracted extrabudgetary funds for the implementation of the project, the costs of creating capital construction facilities, the acquisition of specialized agricultural machinery and equipment within the framework of the project are not taken into account in the part compensated from the federal budget. In addition, the funds allocated by the budgets of the constituent entities of the Russian Federation for state support of projects are not taken into account when determining the minimum amount of extra-budgetary funds attracted for the implementation of the project.

Secondly, there were problems with the transfer of the unused part of the grants to the next reporting periods. The difficulty here lies in the fact that only the Ministry of Agriculture of the Russian Federation directly has the right to make a decision on changing the terms of the concluded Agreement, including on the basis of information and proposals sent by the recipient in case of establishing the need to change the amount of the subsidy specified in the Agreement, including reducing its amount, as well as an increase in the presence of unused limits of budgetary obligations and the condition that the recipient provides information containing a financial and economic justification for this change.

Third, only specialized organizations are allowed to participate in the programs, which significantly reduces the number of potential grant participants and weakens the competition.

Fourthly, we have to state the fact that the deadlines for the adoption of new subprograms are being delayed (by the way, more than twenty of them were originally announced). For example, in light of the sharp rise in the cost of sunflower oil, already at the end of 2020, it was planned to adopt a subprogram "Development of Breeding and Seed Production of Oilseeds in the Russian Federation", which would ensure the breeding of competitive domestic varieties and hybrids of sunflower, soybeans and domestic rapeseed. The project involves the implementation of comprehensive domestic scientific and technical innovative developments of the full cycle aimed at the development of the system of seed production of oilseeds, should ensure a stable growth in industrial production and the sale of high-quality seeds of competitive varieties and hybrids of sunflower, soybeans and rapeseed of domestic selection, the creation of modern diagnostic tools quality control of seeds of varieties and hybrids of sunflower, soybeans and rapeseed. At the same time, at the time of going the publication to print (March 1, 2021), the state spends serious material 
and organizational resources to maintain acceptable prices for sunflower oil for the population, but the subprogram, despite its extreme demand, has not been approved by the Government of the Russian Federation

\section{Conclusions}

1. In Russia, there is no concept of support and development of agriculture that is legally formalized. Today it conditionally replaces by extremely fragmented and not systematized in terms of content and time of adoption a group of program acts of the head of state, numerous acts of the Government of the Russian Federation and the Ministry of Agriculture of the Russian Federation. Formally, these bodies have the right to adopt such acts, but methodologically, this approach seems to be incorrect. In this regard, it is proposed that the foundations of support and development of agriculture be defined in a separate federal law with the discussion of the draft of such a law in the newly created supreme body of power - the State Council of the Russian Federation, which is precisely intended to determine the main directions of domestic policy of priority areas of economic development ( Art. 5 of the Federal Law dated December 8, 2020, No. 394-FZ "On the State Council of the Russian Federation").

2. The existing measures to support the innovative development of the agro-industrial complex have provided a certain positive effect, expressed in the creation of new varieties of seeds, vegetables and poultry. However, in general, the measures taken remain insufficiently effective, primarily due to the imperfection of their legal regulation. Access to support measures is complicated by overly formalized and overloaded legislation, the presence of administrative barriers, and the inflexibility of law enforcement agencies. The solution to this problem is seen in the simplification of legislation on measures to support agricultural manufacturers and processors, the transition to the "one window" principle when registering applications for participation in government programs, as well as allowing the use of unspent funds in the reporting period in the current financial year.

3. It is necessary to introduce or improve additional measures to stimulate the innovative development of the agro-industrial complex. These include concessional lending for agricultural manufacturers, organizations and individual entrepreneurs engaged in innovative production, processing and (or) sale of agricultural products [5]. At the same time, it is important to provide that a preferential short-term or investment loan should be at a rate of no more than $0-2 \%$ and it could be obtained from any of the banks authorized by the Ministry of Agriculture of Russia. In this case, credit institutions should be reimbursed for lost income directly from the federal budget.

4. At the present time, measures for the innovative development of the agro-industrial complex are weakly linked to the strategic goals of the development of Russia, reflected in the Decree of the President of the Russian Federation No. 474 dated July 21, 2020 "On the national development goals of the Russian Federation for the period up to 2030". This gap should be filled primarily by including in the development of new or improving existing federal scientific and technical programs, taking into account the achievements of digitalization and information technology $[4,8,10]$.

\section{References}

1. E. A. Egorov, Zh. A. Shadrina, G. A. Kochian, P. F. Paramonov, Bulletin of Russian Agricultural Science, 5, 4 (2020)

2. A. L. Ivanov, I. S. Kozubenko, I. Yu. Savin, V. I. Kiryushin, Bulletin of Russian Agricultural Science, 5, 4 (2018) 
3. I. S. Kozubenko, I. Yu. Savin, Bulletin of Russian Agricultural Science, 5, 9 (2017)

4. A. V. Kolesnikov, O. Domozhirova, Agroindustrial Complex: Economics, Management, 1, 27 (2020)

5. V. V. Maslova, G. M. Savkina, Agroindustrial Complex: Economics, Management, 2, $29(2020)$

6. V. A. Panfilov, Bulletin of Russian Agricultural Science, 1, 4 (2020)

7. V. A. Panfilov, Bulletin of Russian Agricultural Science, 1, 13 (2019)

8. V. I. Trukhachev, Bulletin of Russian Agricultural Science, 2, 15 (2019)

9. I. G. Ushachev, A. F. Serkov, V. S. Chekalin, M. V. Kharina, agro-industrial complex: economics, management, 1, 3 (2021)

10. V. P. Yakushev, Bulletin of Russian Agricultural Science, 2, 11 (2019) 